[Roberts, P. (2008). Beyond the Rhetoric of "Quality" and "Relevance": Evaluating the Tertiary Education Strategy 2007-12. New Zealand Annual Review of Education, 17, 41-57]

\section{Beyond the Rhetoric of "Quality" and "Relevance": Evaluating the Tertiary Education Strategy 2007-12}

\section{PETER ROBERTS}

\section{Abstract:}

This article provides an overview and critique of the Tertiary Education Strategy 2007-12 (Ministry of Education, 2006). The author sets the Strategy in the context of earlier policy developments in the tertiary education sector. It is argued that while some important changes have been made in the post-1999 "Third Way" years, a number of continuities from the more nakedly neoliberal era of the 1990s are evident. Economic concerns remain dominant in policy thinking, the commodification of knowledge has intensified, new forms of competition have emerged, and the language of reform has not changed as much as might have been expected. The author concludes that there is a certain narrowness of vision in the new Strategy, and that what is needed is deeper reflection on fundamental epistemological and ethical questions.

$\mathrm{I}$

late 2006, the New Zealand government launched its second Tertiary Education Strategy (Ministry of Education, 2006). The Strategy sets out the government's vision and expectations for the tertiary education sector over the period 2007-12. Included with the Strategy is a "Statement of Tertiary Education Priorities 2008-10". The first Tertiary Education Strategy had been released in 2002 (Ministry of Education, 2002). That document concentrated on six major strategies: strengthening system capability and quality, contributing to the achievement of Māori development aspirations, raising foundation skills, developing the skills necessary for a knowledge society, educating for Pacific peoples' success, and strengthening research and knowledge creation and uptake for a knowledge society. The first Strategy had followed the work of the Tertiary Education Advisory Commission
(TEAC, 2000, 2001a, 2001b, 2001c), a body established shortly after the formation of the Labour-Alliance government in 1999 to undertake a comprehensive review of New Zealand's tertiary education system. Through the 1990s, under successive National governments, tertiary education had been dominated by a market ethos, underpinned by appeals to choice, competition and accountability. Despite the major changes inaugurated under National during its three terms in office in the 1990s, it was not until near the end of that decade that the government released its White Paper on tertiary education (Ministry of Education, 1998). Prior to National's election victory in 1990, the fourth Labour government had enjoyed two terms in office and had implemented an extensive programme of neoliberal economic and public sector restructuring (Peters \& Marshall, 1996). In the second of those two terms, Labour had commissioned a report on postcompulsory education and training (Department of Education, 1988) and initiated significant policy changes in the tertiary sector (Department of Education, 1989a, 1989b).

Looking backwards in this way might seem to suggest that tertiary education reform in this country has, for nearly twenty years, been tightly tied to electoral cycles and changes of government. In one sense, this is clearly so. New governments have, even if only belatedly (as was the case with National in the 1990s), produced or supported the release of reports and policy documents bearing their own distinctive stamp. Tertiary education, perhaps more overtly than any other policy area, has served as a beacon for wider social and economic changes. This is in part because high hopes have often been placed on the sector. Tertiary education has been expected to lead the country in forging a new path for economic and social success, however "success" might be defined. Yet, there is also a sense in which tertiary education policy has changed relatively little over the past two decades. Themes that were dominant in discussions relating to the tertiary education sector in the late 1980s are still important today. To understand how and why this might be so, attention must be paid to some of the deeper assumptions underlying the reforms during this period. This paper seeks to do just that, albeit in a modest way, taking the new Tertiary Education Strategy as its starting point. It is argued that some of the trends established in the overtly neoliberal era of the 1990s have continued, and even intensified, under the "Third Way" Labour-led politics of more recent years. (On the nature of New Zealand's approach to "Third Way" politics in relation to tertiary education, see Codd, 2001). 
The first part of the paper provides an overview of the new Strategy. In the second section, critical attention is paid to the key theme of "quality, relevant education" in the Strategy. The final section discusses the continuing emphasis on the economy and competition in current tertiary education and research policy. The paper concludes with brief remarks on some of the strengths of the post-1999 reform period while also drawing attention to the narrowness of the government's vision for tertiary education and the relative lack of imagination in the policy development process.

\section{The Tertiary Education Strategy 2007-12: An Overview}

The Tertiary Education Strategy 2007-12 (Ministry of Education, 2006) is structured in four major parts. The first section provides an introduction and context for the Strategy. This is followed by an explanation of how the government's new a pproach to planning, funding, quality assurance and monitoring for tertiary education organisations will work. The third section details the expected contributions from each part of the tertiary education sector. The final section outlines the government's priority outcomes for tertiary education. The first section is preceded by a Ministerial Foreword, and at the end of the document there is a section on monitoring and evaluation and a glossary. At just 41 pages long, the Strategy is limited in size but not in scope. The discussion includes comments on most areas of the tertiary education sector, and together with the broad outlining of key goals there are various graphs depicting trends in participation, population growth, and the completion of qualifications (among other things). The Strategy is attractively presented, with high quality photographs, plenty of colour, and an easy-to-read layout in each of the main sections.

New Zealand's tertiary education system is seen by the government as "a key asset for our nation" (p. 20). There is a need, however, "to improve the focus on excellent education and research that is relevant to New Zealand and New Zealanders" (p. 20). Having a strategy will be important, it is noted, for the sustainable development of New Zealand as a society and economy and for the realisation of individual goals and aspirations (p. 4). The Strategy, it is noted, will provide "a direction for all tertiary education" (p. 4). The term "tertiary education" covers all post-school education. This includes not just education leading to degrees, certificates and diplomas but also adult and community education, foundation education, and modern apprenticeships. While the focus in the first Tertiary Education Strategy (Ministry of Education,
2002) was on broad and inclusive goals, what is needed now is more concentrated attention on the government's expectations and priority outcomes for the sector. The overriding government goal is "a high income, knowledge-based economy, which is both innovative and creative, and provides a unique quality of life to all New Zealanders" (p. 8). This is, as the government sees it, a process of investing in a plan - a plan that will enable prosperity for all New Zealanders while also recognising the distinctive needs, expectations and contributions of different participating groups in the tertiary education sector. Tertiary education has an important role to play in national development "in all dimensions - social, economic, cultural and environmental" (p. 6).

National and international statistics are employed in support of the government's goals and priorities. Monitoring prior to and during the implementation of the first Tertiary Education Strategy had indicated that the main growth in tertiary education participation had been at the lower levels (level one to four certificates), with participation rates at higher levels remaining steady or declining. New Zealand, it was found, had lower participation rates than a majority of other OECD countries for 15-19 year olds. For students in older age groups, however, the rates were higher than the OECD average. Qualification completion rates have declined for bachelors and postgraduate degrees but remained steady in certificates and diplomas. The proportion of Māori and Pasifika peoples gaining degrees has increased from 1999 to 2005, but the rate of increase for these groups has been slower than for the New Zealand population as a whole (pp. 6-7).

The government aims to: improve literacy, numeracy and language skills; reduce skills shortages by making tertiary education more relevant to the needs of the labour market; continue building research excellence in tertiary education and strengthen the application of this to economic, social and cultural development; increase the number of people completing higher level qualifications; and ensure more New Zealanders have tertiary qualifications before the age of 25 (p. 6). These broad aims are narrowed down to four priority outcomes and elaborated in greater detail in the fourth section of the document (pp. 30-39). In meeting government goals for the tertiary education sector, three themes will be stressed: "Economic Transformation", "Families Young and Old" and "National Identity" (pp. 8-9). These are broad government goals designed to inform policy decisions across the state sector. They do not relate exclusively to the Tertiary Education Strategy. Economic transformation means encouraging high-value 
businesses, well-paid jobs and a highly-skilled workforce. This, it is believed, will accelerate the pace of change in the New Zealand economy. Under the second heading, the government wants to provide families with the support they need to maximise their potential. The aim will be to improve "outcomes for children" and to foster "[g]reater personal wellbeing and security" for individuals, families and whanau (p.9). "National Identity" refers to "pride in who and what we are". This may be through the arts, film, sports or music but it is also defined by our natural environment, our history and our stance on international issues (p. 9).

In implementing the Strategy there will be both challenges and opportunities (pp. 9-10). It is noted, for example, that there is rapid growth in global trade, technological change and international demand for skilled and talented workers. Responding effectively to these trends will require "quality, relevant education and research" to attract the best students and academics to New Zealand, together with an increased international dimension in the tertiary education system (p. 9). The Strategy must also take account of high employment and labour force participation rates. This will mean future economic growth will rely more on higher productivity and better foundation skills and less on increasing the size of the labour force. Productivity increases will come from working closely with industry to meet business needs, supporting a more highly skilled workforce, raising adult workers' foundation skills, and supporting innovation. Demographic changes need to be noted. In particular, it will be important to manage the "baby blip", which will see large numbers of students moving into tertiary education over the next ten years, and to be responsive to the growing diversity of the New Zealand population. Working positively with Māori to develop their assets, resources, knowledge and enterprise will also be vital. Finally, it will be necessary to make sustainable use of natural resources. This will entail encouraging New Zealanders to understand and protect the environment, adding value to primary production, careful management of increased pressure on national resources, and helping to restore indigenous ecosystems and biodiversity.

The Strategy signals the progressive introduction, from 2008, of a new approach to planning, funding, quality assurance and monitoring for tertiary education organisations. The new investment system "will ensure that tertiary education organisations identify, plan for, and meet the needs of students, employers, industry, Māori, community groups and other stakeholders" (p. 13). This will require a shift in focus from "participation and funding" to "achievement and the long term needs of stakeholders" (p. 13). The government expects the Tertiary Education Commission to:

- make more active and considered funding decisions, with controlled funding. Funding will be linked to plans that are negotiated with tertiary education organisations. Those plans define the role of tertiary education organisations in the network of provision and the range and scale of provision the government will fund;

- make investment decisions based on evidence of the quality and relevance of education and research;

- use more diversified and sophisticated approaches to funding a differentiated network of provision;

- take a longer-term view - this means offering greater certainty and stability of funding, and expecting greater investment in capability, quality and sustainable improvement. (p. 13)

Government spending on tertiary education will no longer be demanddriven but instead will be based on a three-year funding path. The new approach will emphasise performance, outcomes, capability development, greater differentiation between different parts of the sector, and the relevance of tertiary education and research for industry, business and community groups. Distinctive but complementary contributions will be expected from universities, polytechnics, Wānanga, private training establishments, adult and community education providers, and industry training organisations. The key to educational success, the Strategy claims, lies in creating quality learning environments where "engaged, effective students" receive "quality teaching" (p. 18). The end result will be "quality, relevance, and excellence in achievement" (p. 18). The different institutions and organisations can, together, contribute to this goal by ensuring success for all New Zealanders through lifelong learning, creating and applying knowledge to drive innovation, and building strong connections between tertiary education organisations and the communities they serve (p. 20). 


\section{Problematising the Discourse of "Quality" and "Relevance"}

The key motif in the new Tertiary Education Strategy is evident from its opening paragraphs. In his Ministerial Foreword, Michael Cullen declares that the focus for New Zealand's tertiary education system should be on "quality and relevant education and research" (Cullen, 2006, p. 2). The Introduction that follows also speaks of the need for "quality, relevant tertiary education for all" (Ministry of Education, 2006, p. 4). The reference to "quality, relevant" education persists throughout the document (e.g., on pp. 9, 13, 21). It has clearly been decided that "quality" and "relevance" will be the current "buzzwords", and no opportunity has been lost in employing them in the Strategy document. On the face of it, this is perplexing. For, there are few terms in policy discourse with more impressive histories of banality and overuse than "quality" and "relevance". On their own, they are devoid of substantive policy content. They immediately beg further questions: Relevant in what ways? For whom? Quality of what kind? As assessed by whom? For what purpose? In relation to what else? Further questions arise when readers consider what is not covered by these terms: How do we distinguish something as irrelevant? If "quality" is what is sought, what is its opposite? The notion of "non-quality" is a nonsense, so is it "low quality" that is to be avoided? If so, low quality relative to what? What are the dividing lines between "high" and "low" quality? Or, if this is a continuum, what are some of the significant points on it and why might these matter for tertiary education? For a document supposedly at the forefront of government policy thinking, the employment of such vacuous and potentially ambiguous terms in such an unreflective way is difficult to understand. There is no evidence of acquaintance with the extensive critical literatures on "quality" and "relevance", and only brief definitions of both terms have been offered (in the Glossary on p. 41 and in two short sentences on p. 21).

It might be argued that it is asking too much of a policy document to expect rigorous interrogation of its own terms and key themes. It could also be noted that this is a strategy document for the tertiary education sector as a whole; it does not set out to address all areas of that sector comprehensively. The Strategy, it could be suggested, is simply a broad overview of key priorities and directions, to which can be added more substantial policy documentation supportive of its main propositions and underlying assumptions. With the first Tertiary Education Strategy (Ministry of Education, 2002), for example, the claim might be made that the TEAC reports constituted evidence and argument of this kind. Yet even there, the relationship between the TEAC process and the development of the Tertiary Education Strategy was somewhat ambiguous. In the draft Strategy document, Steve Maharey (2001), then Associate Minister of Education (Tertiary Education), noted that the strategy had "been informed by a great deal of work already undertaken over the course of the past two years. The Tertiary Education Advisory Commission has produced an impressive body of work, and the Government has already acted on many of the Commission's recommendations." Strangely, there is little explicit acknowledgement of the work of the Commission in the final version of the Strategy. Maharey, in his Ministerial Foreword, mentions the establishment of the Tertiary Education Commission (TEC) as one element of the government's "comprehensive programme of tertiary education reforms" (2002, p.6), but he does not comment on the role played by the Tertiary Education Advisory Commission (from whom the suggestion of an ongoing Tertiary Education Commission had come). The final version of the Strategy does not refer readers back to the TEAC reports for further elucidation or evidence or detail on key points. Indeed, while there are some obvious common themes between the two sets of documents, it is almost as if the work of the Tertiary Education Advisory Commissioners has been preparatory and informative but otherwise left behind. TEAC members are not mentioned by name and the relationship between the work of the advisory commission and the ongoing role of the TEC is not discussed. The first Tertiary Education Strategy is clearly a Ministry document, but there is no indication of who in particular has been responsible for authoring it, or of the extent to which the TEAC reports have influenced the policy development process.

The second Strategy makes more explicit reference to other policy documents and the work of other policy actors in the New Zealand tertiary education context (e.g., in relation to the Performance Based Research Fund (PBRF) and Māori education). A number of overseas sources and international studies are also cited. Important as these references are, they are but a limited sampling of the available literature. There is no mention of work in critical educational policy studies, either in this country or elsewhere. The body of critical work on tertiary education policy alone is extensive, but little of this appears to have informed the development of priorities for the future of the sector. Taking this literature seriously allows policy ideas to be placed in their appropriate historical, social and political contexts. It does not preclude 
the development of a positive, visionary picture of New Zealand's tertiary education future; it simply demands that the assumptions underpinning that vision be subject to rigorous theoretical and empirical scrutiny. There is no one way to undertake critical educational policy research, but the very fact that scholars in this field engage in such vigorous debate demonstrates a common commitment to the value of questioning, investigation and reflective reading. A tertiary education policy document can maintain its focus on broad directions for the sector while also acknowledging (e.g., via footnotes and a detailed bibliography) the breadth, depth and complexity of work in this area. The references included with the strategy are insufficient to provide a robust justification for the proposals advanced or to foster further enquiry. Crucially, the very concepts on which so much of the Strategy document depends - "quality" and "relevance" - find no substantial comment. Critical work on these notions dates back decades. The presentation of such concepts as if they were unproblematic weakens the Strategy considerably. It reinforces the impression that the document is long on rhetoric and short on substance, and runs counter to the claim that this Strategy has a "tighter focus" than the previous one. The persistent appeal to "quality, relevant education" also suggests a lack of imagination and innovation - exactly the qualities the Strategy purportedly seeks to promote. I return to this point later in the paper.

\section{The Continuing Emphasis on Competition and Economic Advancement}

One of the ways the current government has attempted to distinguish its tertiary education policies from those promulgated during the National years of the 1990s is in relation to competition. In the 1990s there was an obsession with the promotion of "student choice" through greater competition between tertiary education providers. Wedded to a more nakedly neoliberal ideology, National politicians and policy makers advanced the view that students would "vote with their feet" and that tertiary education institutions and organisations would stand or fall on the basis of their ability to meet "consumer needs". Structural and legislative changes provided strong incentives for the growth of the private tertiary education sector, and a vigorous ethos of competition for student enrolments (and the government subsidies that followed them) was initiated (Peters \& Roberts, 1999; Olssen, 2001). Over the past eight years, Labour ministers (and particularly those responsible for tertiary education) have made a concerted push to distance themselves from this era of numbers-driven competition. Greater emphasis has been placed on cooperation, collaboration and the development of concentrations of research excellence. This message is reinforced in the latest Strategy.

Yet, competition in the tertiary education has by no means disappeared. In some respects, it has become more intense. The development of the Performance Based Research Fund, in particular, has led to the emergence of new forms of competitive behaviour within and between institutions. University leaders know how much is at stake in PBRF assessment rounds, two of which have been completed so far, and a great deal of institutional time and effort has been devoted to the preparation of evidence portfolios and other PBRF materials. The results, when favourable, confer important "bragging rights" and these are essential in attracting international students and academics. Following the 2003 assessment exercise, the University of Auckland felt justified in asserting its status as the premier research university in the country, having scored higher than all other institutions on the key indicators of overall performance. The results of the 2006 round (a "partial" round) were less clear cut, with the University of Otago edging ahead of the University of Auckland on one crucial indicator. This led to a high profile battle of words between leaders of the two institutions, demonstrating just how competitive the sector remains. Beyond this battle "at the top", the PBRF has sharpened divisions between the traditional universities and other tertiary education institutions (including not just polytechnics but Auckland University of Technology (AUT) as a "new" university of technology). The PBRF has also fostered a new spirit of competition within universities, and is now available - for those who make their scores known - as another means for distinguishing between academics. Even where individual academics do not reveal their scores, results across disciplines in the assessment exercise are a matter of public record and provide fodder for comparisons between departments and faculties within universities.

The emphasis on competition has continued in other ways. Senior Labour politicians have made much of the fact that New Zealand needs to become competitive in the global economy, and this view is reflected in key policy documents such as the new Strategy. Labour's stance on globalisation has been overwhelmingly positive over the past eight years. It has been taken as given that New Zealand must participate actively in the global economy. We need, the Strategy and other documents insist, to "add value" to goods and services and market ourselves effectively on the international stage. Few critical questions 
have been asked about globalisation. A determined effort has been made to secure a free trade agreement with China, but little has been said about the differences between "free" trade and "fair" trade. Constant references have been made in recent years to the need to move New Zealand further up tables of economic performance relative to other countries in the OECD. In short, there has been a strong and unswerving commitment to international economic competitiveness, and almost every major policy document produced over the past eight years has been promoted at least partly on the basis of supporting this goal.

In the case of the second Strategy, this goal is accorded primary importance. "Economic transformation" is the first of the three themes identified as significant in the Strategy. The other themes are not unimportant, but they are clearly secondary to this overriding goal. This is evident in what is not said as much as what is said. When the Strategy mentions social aims, there is a definite lack of detailed argumentation. It is as if those writing the Strategy want to acknowledge the social value of tertiary education but do not know really know what to say, beyond rudimentary rhetorical statements, in doing so. This is especially noteworthy when set against the backdrop of discourses on the creation of a knowledge society and economy. The idea of building a "knowledge society and economy" has been a cornerstone in Labour's suite of policy reforms over the past eight years. As time has passed it has become increasingly clear that it is very much the economic aspect of this ideal that has come to dominate (Roberts, 2005). Little has been said about what a knowledge society might look like. One of the few policy initiatives from the past decade where this has been considered, even if only in a limited way, was the Foresight Project - sponsored by the National government in its final term in office in the 1990s (see Ministry of Research, Science and Technology, 1998). In the years following that initiative, little substantial government work has been conducted in this area - despite the fact that the "knowledge society and economy" ideal has been central to almost every major shift in economic and social policy since Labour took office in 1999. The first TEAC report (TEAC, 2000) has perhaps come closest to what might be required in taking these questions seriously, but that document still provided more of a broad canvassing of ideas than an in-depth, critical examination of the knowledge society.

It is not that economic competitiveness has been the only government goal in recent years. Improving participation and results for
Māori and Pasifika students in education has also been a priority. The second Strategy notes, for example, that a separate Māori tertiary education strategy is being prepared and implies that careful attention will have to be paid to this. There has also been much greater attention paid to adult and community education over recent years. It is important to acknowledge this, as it has been one of the most neglected areas of tertiary education policy in the past. The government's support for the Tripartite Forum, bringing unions, the Vice-Chancellors and government together in discussions of salaries and conditions of work for academics, should also be noted. This commitment provides an indirect challenge to the competitive model of tertiary education salary bargaining, where unions are pitted against Vice-Chancellors (as Chief Executive Officers and "the Employer" in their institutions) and each university seeks to outdo the others in securing remuneration and conditions that will be attractive on the international academic job market. More money has been devoted to social welfare under the Labour-led governments of recent years than was the case under National in the 1990s, and some of this (e.g., financial assistance for students from impoverished backgrounds) has had a direct impact on tertiary education participation and success.

What is lacking is a certain depth and complexity in thinking about the knowledge society, and the social sphere more generally, prior to or in tandem with policy work on tertiary education. The lack of detailed, rigorous attention to the idea of a knowledge society is evident at the most fundamental level: the notion of "knowledge" itself has been explored in only a relatively superficial manner. Key epistemological questions have been largely ignored. Readers of the two Tertiary Education Strategy documents (Ministry of Education, 2002, 2006) gain little sense of how knowledge has been understood by thinkers in the past or of how it might be distinguished from skills, information, opinions, ideas, or beliefs. In these and other key policy documents, it would be difficult for a reader to gain the impression that knowledge has been debated and discussed for centuries. How is knowledge acquired? What does it mean to "know"? What are the different forms of knowledge? Does knowledge have intrinsic value? To what extent and in what ways are human beings constructed by different conceptions and practices of knowledge creation? Does all research lead to "knowledge"? These questions, and others like them, find few answers. 
It is perhaps hardly accidental that basic epistemological questions are ignored, despite the apparent significance of "knowledge" in policy documents over the past eight years. For enhancing the pursuit of knowledge per se is not the point of the reform process. Knowledge is, in many respects, incidental in a system driven primarily by economic imperatives. What matters most is performance, and "knowledge" becomes useful to the extent that it can support this. Knowledge has become very much a commodity and is now seldom distinguished from other goods and services (cf. Lyotard, 1984). Under Labour, there has been considerable emphasis on growing "knowledge industries" and on "export education". In the Tertiary Education Strategy 2007-12 there is little to separate "knowledge" from "skills". Even critical thinking becomes reduced to just one of several "highly developed skills" (p. 23). The notion of critique finds virtually no discussion. The role of universities in serving as the "critic and conscience of society", a legal requirement in New Zealand, barely warrants a mention (see p. 9). The commodification of knowledge has been pushed even further with the entrenchment of an outputs-driven, measurement-oriented approach to research under the PBRF (See further, Codd, 2006; Roberts, 2006).

\section{Concluding Comments}

Underlying the Tertiary Education Strategy, 2007-12 and most other key policy documents from recent years is the overarching goal of improving New Zealand's international economic competitiveness. The aim has been to develop a "shared national vision", but this vision is itself circumscribed by the rules of the global market. The vision we are invited to share places a premium on skills, creativity and enterprise for economic success under conditions of globalisation. A wide range of more specific goals can be pursued - provided they fall within this framework. Thus, there is now reference to the environment, as if this has only recently become important, but this is couched within the economic discourse of sustainability. Sustainability, it is made clear, is good for economic competitiveness. Similarly, the new Strategy makes "Families Young and Old" a key theme, but little is said about the nature of families or communities and their significance for tertiary education policy. The Strategy makes the extraordinary claim, without argument, that " $[t]$ he kinds of knowledge, skills and competencies that enable people to succeed in a knowledge-based economy are increasingly similar to those that enable people to enjoy and contribute positively to their families and communities" (p. 21). This revealing comment indicates just how narrow the government's vision has become. There is only one way to live our lives, it seems, whether we are at work or at home with our families. This framing of policy sets significant limits on the development and pursuit of other social ideals. It represents, as much as anything else, a failure of imagination in the policy development and implementation process.

In reading the Tertiary Education Strategy 2007-12 it is not difficult to experience a strong sense of déjà vu. There is a certain "sameness" in many of the education policy documents produced in this country over the past two decades. The underlying narrative, whether the policy document has been released by a National-led government or a Labourled government, runs something like this: the world is undergoing rapid economic change; New Zealand will need to be clever and innovative if it is to adapt to this changing world; education can and ought to play a key role in this process. The new Tertiary Education Strategy does not break from this mould. The "sameness" is not limited to similarities in the underlying narrative. The language employed in many of the documents appears to have been lifted, as it were, from a single policy writing manual. This is, despite the ostensible shift away from the "more market" orientation of the 1990s, still in many respects the language of neoliberalism. The first Strategy includes references to "consumers", "users" and "providers"; it speaks of "adding value" and "performance indicators". This sort of language is less prominent in the second Strategy, but other words and phrases that seem to be compulsory in every major policy statement are well to the fore. These include "innovation", "challenges and opportunities", "excellence", "success", "competencies", "productivity", "up-skilling", and "lifelong learning". There is also a high degree of homogeneity in the layout and style of such documents, with relatively short discussion sections, plenty of bullet points, sidebar items on more specific topics, and the generous use of colour. The TEAC reports (TEAC, 2000, 2001a, 2001b, 2001c) stand out as something of an exception here. They are more substantial, well argued and better researched than both the Strategy documents and the Tertiary Education Review Green and White Papers (Ministry of Education, 1997, 1998 respectively) of the 1990s. But the TEAC reports merely informed later official policy statements; they were documents produced by an advisory commission rather than a policy making body. The TEAC reports were read by researchers in the field of tertiary education in New Zealand but the two Strategy documents have been circulated much more widely. 
Credit must be given to the government post-1999 for some important and worthwhile changes in the tertiary education sector. The very fact that the Labour-Alliance coalition government was willing to form an advisory commission with a membership that included several senior academics was a significant step forward, after the officials-driven policy development processes of the immediately preceding years. There has been a genuine attempt, in some areas of policy at least, to draw on scholarly expertise and experience. The TEAC reports have provided the most thorough government-sponsored examination of tertiary education in two decades. There is no longer an appeal by Ministers or other government officials to "the market" as the solution to all problems in the tertiary education sector. More serious attention has been paid to the education of Māori and Pasifika communities. Instead of seeking to blur all boundaries in the tertiary education sector, the government, through the latest Strategy and other developments, has demonstrated a willingness to recognise the distinctive contributions made by different tertiary institutions and organisations. At the same time, I have suggested, much has not changed in tertiary education policy. Economic concerns remain dominant, competition continues to be fostered, the commodification of knowledge has intensified, and the language of the two Strategies bears more than a passing resemblance to the language employed in many other policy documents over the past two decades.

\section{References}

Codd, J. (2001). The third way for tertiary education policy: TEAC and beyond. New Zealand Annual Review of Education, 10, 31-57.

Codd, J. (2006). The PBRF and the production and commodification of knowledge. In L. Bakker, J. Boston, L. Campbell, \& R. Smyth (Eds.), Evaluating the Performance-Based Research Fund: Framing the debate (pp. 221-235). Wellington: Victoria University Institute of Policy Studies.

Cullen, M. (2006). Foreword. In Tertiary education strategy 2007-12. Wellington: Ministry of Education (Office of the Associate Minister of Education - Tertiary Education).

Department of Education. (1988). Report of the working group on post-compulsory education and training (Hawke Report). Wellington: Department of Education.
Department of Education. (1989a). Learning for life: Education and training beyond the age of 15. Wellington: Department of Education.

Department of Education. (1989b). Learning for life II: Policy decisions. Wellington: Department of Education.

Lyotard, J.-F. (1984). The postmodern condition: A report on knowledge (G. Bennington \& B. Massumi, Trans.). Minneapolis: University of Minnesota Press.

Maharey, S. (2001). Foreword. In Tertiary education strategy (draft). Wellington: Ministry of Education (Office of the Associate Minister of Education - Tertiary Education).

Maharey, S. (2002). This strategy: Ministerial Foreword. In Tertiary education strategy, 2002/07. Wellington: Ministry of Education (Office of the Associate Minister of Education - Tertiary Education).

Ministry of Education. (1997). A future tertiary education policy for New Zealand: Tertiary education review (Green Paper). Wellington: Ministry of Education.

Ministry of Education. (1998). Tertiary education in New Zealand: Policy directions for the 21st century (White Paper). Wellington: Ministry of Education.

Ministry of Education. (2001). Tertiary education strategy (draft). Wellington: Ministry of Education (Office of the Associate Minister of Education - Tertiary Education).

Ministry of Education. (2002). Tertiary education strategy, 2002/07. Wellington: Ministry of Education (Office of the Associate Minister of Education - Tertiary Education).

Ministry of Education. (2006). Tertiary education strategy 2007-12. Wellington: Ministry of Education (Office of the Minister for Tertiary Education).

Ministry of Research, Science and Technology. (1998). Building tomorrow's success: Guidelines for thinking beyond today. The Foresight Project. MoRST: Wellington.

Olssen, M. (2001). The neo-liberal appropriation of tertiary education policy in New Zealand: Accountability, research and academic freedom. "State-of-the-Art" Monograph No. 8. Palmerston North: New Zealand Association for Research in Education.

Peters, M., \& Marshall, J. (1996). Individualism and community. London: Falmer Press. 
Peters, M., \& Roberts, P. (1999). University futures and the politics of reform in New Zealand. Palmerston North: Dunmore Press.

Roberts, P. (2005). Tertiary education, knowledge and neoliberalism. In J. Codd \& K. Sullivan (Eds.), Education policy directions in Aotearoa New Zealand (pp. 39-51). Melbourne: Thomson Dunmore Press.

Roberts, P. (2006). Performativity, measurement and research: A critique of performance-based research funding in New Zealand. In J. Ozga, T. Popkewitz \& T. Seddon (Eds.), World yearbook of education 2006: Education research and policy (pp. 185-199). London: Routledge.

Tertiary Education Advisory Commission. (2000, July). Shaping a shared vision. Wellington: TEAC.

Tertiary Education Advisory Commission. (2001a, February). Shaping the system. Wellington: TEAC.

Tertiary Education Advisory Commission. (2001b, July). Shaping the strategy. Wellington: TEAC.

Tertiary Education Advisory Commission. (2001c, November). Shaping the funding framework. Wellington: TEAC.

\section{The author}

Peter Roberts is Professor of Education at the University of Canterbury. His primary areas of scholarship are philosophy of education and educational policy studies. He has research interests in the work of Paulo Freire, literature and education, the ethics and politics of education, and tertiary education policy, among other areas. He has published widely in international journals and edited collections. His books include Education, Literacy and Humanization: Exploring the Work of Paulo Freire (Westport, CT: Bergin and Garvey, 2000), University Futures and the Politics of Reform (with Michael Peters, Palmerston North, Dunmore Press, 1999), and Digital Developments in Higher Education: Theory and Practice (edited with Mark Chambers, Cambridge, Taylor Graham Publishing, 2001). 